\title{
Nurses: Advocating, Leading, Caring!
}

\author{
Stephanie L. Ferguson*
}

This speech was delivered on 27 October at the 2012 Conference and general meeting of the Italian Nurses Association CNAI (Consociazione nazionale delle Associazioni infermiere/i) held in Rome from 25 to 27 October 2012. The theme of the conference was "No Nurses No Future". The "No Nurses No Future" is a national campaign developed by the nurses of the Italian Nurses Association to fight for the rights of the profession to sustain not only the practice of the nurse, strong nursing education, research and regulation, but more importantly to ensure that in the future there will be enough nurses in the healthcare workforce to advocate, lead and care for the citizens of Italy.

Italian nurses took advantage of the presence of prof. Ferguson and, before travelling to Rome, the Region Lombardy IPASVI Colleges (Coordinameno dei Collegi IPASVI della regione Lombardia) invited her to talk on the same topic during a jointed Conference with CNAI at Circolo della Stampa of Milan on 23rd October.

NURSES - ADVOCATING, LEADING, CARING!

This is a time of great challenge and great opportunity in global healthcare. As nurses and midwives, we are in a position of strength in confronting the challenges to human health that we face; yet we are vulnerable to broader instabilities within our societies that threaten to undermine our professional effectiveness. Many governments and policymakers are not paying attention or being proactive to address nursing workforce issues.

I commend the Italian Nurses Association for creating an innovative campaign to fight for the rights of the nursing profession and to demand that their nation wake up and realize if there are no nurses leading, teaching, practicing, conducting research, advocating and caring for the people of Italy, there will be no future for the country. I argue that an Italy with no nurses would be a global disaster, a tragedy not only in Italy, but Europe and the world.

The "No Nurses No Future Campaign" aligns with the nursing principles of advocating, leading and caring. The most acute challenge we face are health care budgets tightening in parallel with an increase in the demand for high quality healthcare, globally. The opportunity we have is to face this challenge by consolidating our role as leaders in health, leaders in social equality and leaders in social stability. This demands of us that we acknowledge weaknesses in healthcare systems, weaknesses that threaten to undermine our work, and combine our strengths as professionals to shape healthcare systems charac-

* Director, ICN LFC Programme and Facilitator, Global

Nursing Leadership Institute

International Council of Nurses terized by responsiveness, efficiency and effectiveness. We as nurses have to advocate for quality healthcare for all like never before.

As advocates, we have to understand some of the most pressing challenges for nursing in our nations and work together to create the change we know is needed and we know we can achieve. One of my professional and personal roles is to rouse strength and optimism within the nursing profession in order for each and every one of you, and your millions of colleagues worldwide, to seize the opportunity to advocate for and lead towards better health care for all. As advocates, leaders and care givers it is our role:

$>$ To ensure we have evidence of Nursing Effectiveness and deliver that evidence ourselves at the health policy making levels.

$>$ To ensure we have Human Resources to serve the populations we care for, and that we gain long term sustainable support for these resources at the health policy making level.

$>$ To ensure we have long term and sustainable resources to overcome HIV/AIDS, TB, Malaria and non-communicable diseases.

$>$ To forge and sustain strong partnerships within nursing, strong inter-professional partnerships within healthcare systems and strong partnerships with the public we care for.

$>$ To build and sustain nursing leadership through advocacy for a greater role in health policy making and greater support for the quality care we deliver.

$>$ To develop our policy voice as advocates and shape effective health policies critical for patients, nurses/nursing and strong health care delivery systems. 
$>$ To ensure our governments understand the impact of our work in caring for the public is critical and must receive greater support. The "No Nurses No Future campaign" is a perfect example of nurses advocating on behalf of themselves and on behalf of the public we care for. Indeed, we must seize every opportunity to make the case that investing in nursing is to invest in better public health and higher standards of living for all.

$>$ To state boldly that nurses are strong advocates caring for the world's most vulnerable and victimized populations.

$>$ To ask essential questions of our political, corporate and professional leaders, and of ourselves.

As nurses our roles are numerous and demanding, from the vital care we deliver every day, to the policy we shape and drive forward. From the fear and pain we alleviate, to the hope and prosperity we foster, our work is of tremendous importance at every level within our communities and nations, and it is our responsibility to ensure that is justly supported by our political leaders in order that it is universally enjoyed by the public we care for.

As nurses, we must be dedicated to the highest standards of care, to equality and respect for all. This dedication to quality standards of care and equality and respect for all also includes having a strong knowledge of health policy, politics and political skills. We must have a keen understanding of the relationship between policy development and politics.

We have to be results driven and demand that those we work with produce results as well. We have to be strategic in our management of health systems and unconditional in our requirement that nursing have a strong and central role in health system management and policy making. Our advocacy skills must be diplomatic in nature, combining effective communication skills as well as networking and partnership strategies. Indeed, we must exude our power to build and sustain networks as advocates, leaders, and care givers.

As advocates and leaders in care delivery:

$>$ We must "fight" for access to services for those most in need and most vulnerable.

$>$ We must forge partnerships to achieve great goals in public health.

$>$ We must sustain our partnerships and networks, keep them active and keep them working towards a unified purpose. Remember, there are no permanent friends or enemies in policy making and politics.

As nurses, we all need constantly to develop our leadership capacity. Leadership development is a life journey. At the International Council of Nurses (ICN), we believe leadership today requires us to bridge the divides of race, class, gender, culture and nationality. Nursing epitomizes the reality that we do not overcome common, global challenges within a divided framework, we overcome through a unity of purpose and energy. Nurses are ideally suited to lead and promote unity across communities, societies and nations.

Effective leaders must be visionary and strategic in order to garner support and be effective in modern health care. These are attributes we must foster from within. Self-confidence and confidence in the power of nursing are essential to this. We must not shy away from bringing evidence as to the value of our work to the fore; in fact it is imperative that we do so. Our work, our skills and our knowledge are the foundation of our leadership. Indeed our work, our skills and our knowledge are the justification for our role as leaders.

Nursing leadership is not a novel idea, nor is it a new or recent phenomenon. Historically, nurses have been leaders in healthcare. The innovation I am proposing here is for nursing leadership to become explicit and active and visible at the highest levels of policy making, where it was once implicit and poorly represented at the policy table. This innovation is the fruit of many efforts, of many victories won over many years by individuals and groups such as CNAI, the Italian Nurses Association. This innovation, this great change in the way our health systems, and indeed our societies, are being managed, is one that all nurses must embrace through advocacy, leadership and care.

I want to address some of the more pragmatic and important challenges for nursing leaders in a globalised world. Strengthening the health workforce and building a positive workplace is the key issue in recruitment and retention. Nurses want better pay and working conditions, opportunities for continued education, a voice in decision-making, and to be respected and valued for what they know and do.

Another point is effectively influencing policy. For nursing leaders, the challenge lies in securing a seat at the policy table and making our voice heard. Without that voice, policy will be incomplete. We need to be involved in shaping not just nursing and health policy, but in influencing social policy as well. In fact, nursing has an obligation to take an active part in policy development and related decisions at all levels, for the benefit of society. We need to instil this in all nurses.

As a profession, nursing must buttress it's foun- 
dations in order to ensure effective leadership. We need transparent, sound governance in nursing and in health care. This means we need up to date, relevant nursing policy, standards, processes, competencies and reporting.

Technology, health system reforms and redesigns, human resource imbalances, politics, changing demographics and disease patterns, scientific advances and other factors offer new opportunities. Governments and employers in many countries are ready to embrace shared and new competencies for nurses and it is our responsibility as nurses to take the lead in further driving this trend.

Nurses are on the front lines of healthcare delivery in every country in this world, they are best placed to report on needs and advocate for and deliver the most effective responses to the needs of the people we care for and work with. Our most fundamental responsibility is to the public and to ourselves, and we must lead health systems in supporting that responsibility.

In the absence of nurse leadership, governments, cash-strapped employers, and un or ill-informed policy groups and donors could easily promote what they see as cheap, quick options for service delivery, despite evidence to the contrary (i.e. health care assistants, nursing auxiliaries and similar non-professionals). To prevent this, nursing must show its value and promote our full utilisation in meeting the needs of the populations we serve. We do this each and every day as leaders, as advocates as caregivers. The challenge is to create and seize the opportunities. Whether they are initiatives that help fill gaps in service delivery, address education, research, policy or politics. New ventures will widen the scope of nursing activity into the broader health and social issues we face.

\section{BIBLIOGRAPHY}

Ferguson, S., (2012) Taking Action. Ugandan Nurses Leading Health Policy Change. In Mason, D., Leavitt ,J.K., Chaffee, M.W. (eds.), Policy \& Politics in Nursing and Health Care. 6th edition, St. Louis: Saunders ELSEVIER, 722-726.

Ferguson, S., (2008) Thriving while working on the edge: Nurses leading change worldwide. International Nursing Review, 55(4), 367-368.

International Council of Nurses, (2010) ICN Leadership for ChangeTM Program Brochure. Retrieved from www.icn.ch/leadchange.htm.

International Council of Nurses, (2007) Health policy package: A guide for policy development. Geneva, Switzerland: International Council of Nurses.

Mason, D., Leavitt, J.K., Chaffee, M.W. (eds.), (2012) Policy \& Politics in Nursing and Health Care. 6th edition, St. Louis: Saunders ELSEVIER.

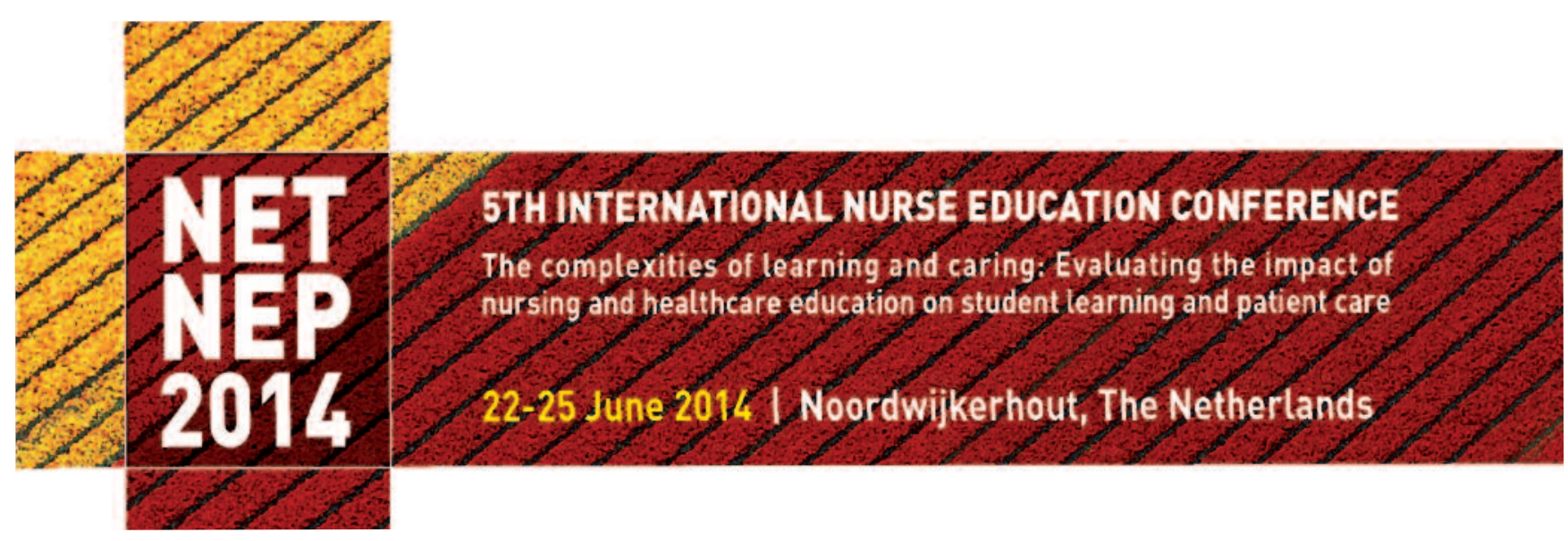

